\title{
Use of Selected Lactobacilli to Increase $\gamma$-Aminobutyric Acid (GABA) Content in Sourdough Bread Enriched with Amaranth Flour
}

\author{
Manuel Venturi ${ }^{1}{ }^{1}$, Viola Galli ${ }^{2, *}$, Niccolò Pini $^{2}$, Simona Guerrini ${ }^{1}\left(\mathbb{C}\right.$ and Lisa Granchi ${ }^{2}$ \\ 1 FoodMicroTeam s.r.l., Via di Santo Spirito, 14, 50125 Florence, Italy; manuel@foodmicroteam.it (M.V.); \\ simona@foodmicroteam.it (S.G.) \\ 2 Department of Agriculture, Food, Environment and Forestry (DAGRI), University of Florence, \\ Piazzale delle Cascine, 18, 50144 Florence, Italy; niccolo.pini@unifi.it (N.P.); lisa.granchi@unifi.it (L.G.) \\ * Correspondence: viola.galli@unifi.it; Tel.: +39-055-2755917
}

Received: 14 May 2019; Accepted: 13 June 2019; Published: 18 June 2019

\begin{abstract}
Aminobutyric acid (GABA) is the primary inhibitory neurotransmitter of the central nervous system and possesses various physiological functions. GABA production can be obtained thanks to lactic acid bacteria activity in different foods such as sourdoughs. Recently, breads made from blends of pseudocereals and wheat flours have attracted much attention. Amaranth is especially interesting because of its high nutritional value, having a high protein content and containing different antioxidant compounds. Therefore, this study aimed to obtain sourdough breads enriched with GABA thanks to bacterial activity and to investigate the effect of amaranth flour addition on the antioxidant and sensorial properties of bread. Eighteen lactobacilli strains were assayed for GABA production in amaranth and wheat flour liquid sourdoughs. Two strains, Lactobacillus brevis A7 and Lactobacillus farciminis A11, demonstrated high GABA producing capability; hence, they were used to prepare breads containing $20 \%$ amaranth flour. The results confirmed the capability of the two strains to increase GABA concentrations (up to $39 \mathrm{mg} / \mathrm{kg}$ ) in breads. Samples with amaranth addition showed a significantly higher total phenolic content compared to the control bread (more than $15 \mathrm{mg}$ GAE $100 \mathrm{~g}^{-1} \mathrm{dwb}$ ); sensory analysis showed that breads with amaranth were moderately acceptable. Nevertheless, their general liking evaluation was significantly lower compared to the control bread. The addition of pseudocereal to traditional wheat sourdough and selection of lactobacilli allowed the production of baked goods with enhanced GABA content and antioxidant capacity, but recipes have to be developed to increase the organoleptic acceptability of the final products.
\end{abstract}

Keywords: sourdough; $\gamma$-aminobutyric acid GABA; amaranth flour; lactobacilli; bioactive compounds

\section{Introduction}

Sourdough fermentation represents a traditional biotechnology able to improve and enhance the overall quality of leavened bakery goods obtained using a wide variety of flours [1]. Due to the activity of the occurring microbiota (lactic acid bacteria and yeasts) and the long fermentation times, sourdough positively influences the final products, improving flavour, texture, shelf-life, and above all the nutritional and functional features of the final product [2-4]. Particularly, the metabolic capability of lactic acid bacteria (LAB) is fundamental to obtain these distinctive characteristics. For instance, microbial activities toward cereal proteins, such as decarboxylation, deamination, transamination, and side chain modification, may lead to the production of several compounds which have an impact both on the nutritional quality and the flavour of bakery products [5-9]. In this context, the production of bioactive compounds, such as $\gamma$-aminobutyric acid (GABA), by LAB during sourdough 
fermentation could be particularly attractive [10,11]. $\gamma$-aminobutyric acid, a non-protein aminoacid, has several physiological functions in humans: Diuretic and hypotensive activity, a tranquillizing effect, and it acts as an inhibitory neurotransmitter in sympathetic brain function [10,12-15]. In fact, foods fortified with GABA are efficient in the regulation of sleeplessness, autonomic disorders, and depression $[10,16]$. GABA is produced from the irreversible $\alpha$-decarboxylation of L-glutamic acid, catalysed by a specific enzyme, glutamic acid decarboxylase (GAD), found in bacteria, plants and animals $[5,10,17]$. Some works have already shown the presence of GAD activity in LAB [18-20]. In this regard, fermented foods represent an excellent source of dietary GABA [5]. Furthermore, as a stable part of diet worldwide, cereal-based products enriched with GABA are of particular interest. GABA enrichment of baked goods by exploiting selected LAB, belonging to various species, has been obtained using different flours [10,11,18,19,21]. Diana et al. [11] used a strain of Lactobacillus brevis, isolated from cheese, for the manufacture of wheat bread with a final GABA content of $24.2 \mathrm{mg} / 100 \mathrm{~g}$. Strains of Lactococcus lactis and Lactobacillus plantarum isolated from cheese were used for the production of a bread GABA enriched, using a mixture of pseudocereals and leguminous flours [18]. The selection of peculiar cereals or pseudocereals, based on their nutritional potential, may be very useful to improve the technological and functional features of baked goods [22]. Indeed, the successful replacing of standard wheat flour with unconventional flours pseudocereal or legume flours has been demonstrated $[22,23]$. Whole pseudocereal grains such as quinoa, amaranth, and buckwheat have abundant content of different compounds, i.e., vitamins, fatty acids, flavonoids and phenolic acids, with a known positive impact on human health [24-27]. For these reasons, an increment of these cereals' consumption in the daily human diet has been recommended [24,28-30]. Among the pseudocereal group, amaranth is of particular interest because of its high nutritional value, having a high protein content, a high concentration of essential aminoacids [31], and containing different antioxidant compounds. Hence, the potential of sourdough fermentation, combined with amaranth supplement, could be a tool to develop new healthy baked products. Nevertheless, the sensory quality of the final products has to be taken into account since it is strongly influenced by the addition of amaranth flour [32]. Therefore, this study aimed to screen GABA-producing lactobacilli in order to obtain naturally GABA-enriched sourdough breads, and concurrently to investigate the effect of $20 \%$ addition of amaranth flour on the antioxidant properties of the final products. The sensory quality of the breads was also evaluated to determine the contribution of lactobacilli fermentation and amaranth flour addition on the organoleptic characteristics.

\section{Materials and Methods}

\subsection{Lactobacilli Strains and Culture Conditions}

Eighteen lactobacilli strains of five species (L. brevis, L. farciminis, L. plantarum, L. rossiae and L. sanfranciscensis), previously isolated from six Italian sourdoughs and belonging to the culture collection of the Department of Agriculture, Food, Environment and Forestry (DAGRI) of the University of Florence, were used in this study (Table 1).

Table 1. Lactobacilli strains and the isolation source.

\begin{tabular}{cc}
\hline Lactobacilli Strains & Italian Sourdough \\
\hline L. brevis A7; L. farciminis A11 & Schiacciata (flat, salty bread) \\
L. brevis B1; L. sanfranciscensis B3; L. farciminis B5; L. farciminis B7; L. rossiae B6; L. farciminis B8 & Bread \\
L. plantarum C2 & Tuscan bread \\
L. brevis Ga1; L. rossiae Ga11; L. rossiae Ga12; L. rossiae Ga14; L. sanfranciscensis Gd44; L. rossiae Gd63 & Lagaccio biscuit \\
L. farciminis H3 & Ancient grain bread \\
L. rossiae O1; L. plantarum $\mathrm{O} 4$ & Panettone cake \\
\hline
\end{tabular}




\subsection{Liquid Sourdough Fermentations}

The lactobacilli strains, grown overnight in MR3i broth [33], were singly inoculated $(9.0$ log $\mathrm{CFU} / \mathrm{mL}$ ) into wheat and amaranth flour doughs. The sourdoughs were prepared by mixing water and flour to obtain a dough yield (DY), i.e., the percent ratio of the weight of the dough to the weight of the flour, of 333 and 667, for wheat and amaranth liquid sourdoughs, respectively. The samples were incubated for $6 \mathrm{~h}$ at $30^{\circ} \mathrm{C}$ under stirring conditions (ca. $100 \mathrm{rpm}$ ). Control and acid control doughs (acidified to $\mathrm{pH} 3.5$ by lactic acid addition) without bacterial inoculum were prepared and incubated under the same conditions. At the end of the fermentation time, sourdough samples were taken in order to perform analysis of GABA content and select the highest-GABA-producing lactobacilli strains.

\subsection{Sourdough Fermentation and Bread Making}

Six breads were prepared according to the recipes reported in Table 2. For each bread, a prefermented dough was prepared. Four doughs were inoculated with only baker's yeast (termed as PFC W, PFAC W, PFC Am and PFAC Am) and two with the inoculum of baker's yeast and the selected lactobacilli strains: Lactobacillus brevis A7 and Lactobacillus farciminis A11 (termed PFSD A7 and PFSD A11, respectively) (Table 2).

Table 2. Recipes for pre-fermented dough manufacture and bread making and related dough yield (dough weight $\times 100$ /flour weight). PF-prefermented; C-control; AC-acid control; SD—sourdough; W-wheat flour; Am-Amaranth flour; A7—L. brevis A7 strain; A11—L. farciminis A11 strain.

\begin{tabular}{|c|c|c|c|c|c|c|}
\hline \multicolumn{7}{|c|}{ Prefermented Dough } \\
\hline Ingredients ( $\%$ on Total Flour) & PFC W & PFAC W & PFC Am & PFAC Am & PFSD A7 & PFSD A11 \\
\hline Wheat flour & 100 & 100 & 80 & 80 & 80 & 80 \\
\hline Amaranth flour & - & - & 20 & 20 & 20 & 20 \\
\hline Water & 58 & 58 & 58 & 58 & 58 & 58 \\
\hline Baker's yeast & 1 & 1 & 1 & 1 & 1 & 1 \\
\hline L. brevis A7 (log (CFU/g)) & - & - & - & - & 9 & - \\
\hline L. farciminis A11 (log (CFU/g)) & - & - & - & - & - & 9 \\
\hline \multicolumn{7}{|c|}{ Bread } \\
\hline Ingredients (\% on total flour) & $\mathrm{CW}$ & $\mathrm{ACW}$ & C Am & AC Am & SD-A7 & SD-A11 \\
\hline Prefermented dough & 50 & 50 & 50 & 50 & 50 & 50 \\
\hline Wheat flour & 100 & 100 & 80 & 80 & 80 & 80 \\
\hline Amaranth flour & - & - & 20 & 20 & 20 & 20 \\
\hline Water & 58 & 58 & 58 & 58 & 58 & 58 \\
\hline Dough yield & 158 & 158 & 158 & 158 & 158 & 158 \\
\hline
\end{tabular}

Amaranth flour was added as $20 \%$ of the total flour in four doughs; acid control doughs were acidified by lactic acid to 3.5. The prefermented doughs were fermented for $18 \mathrm{~h}$ at $30^{\circ} \mathrm{C}$ and then added to the final mixtures. In the final dough (Table 2) the ingredients were added at the same time and mixed for $10 \mathrm{~min}$ in a twin arms mixer (model RS12, Bernardi, Italy). The doughs were placed in the trays at $30{ }^{\circ} \mathrm{C}$ with $88-90 \%$ relative humidity for $3 \mathrm{~h}$. Samples were taken at the beginning and at the end of the leavening time. Finally, doughs were baked at $180^{\circ} \mathrm{C}$ for $15 \mathrm{~min}$.

\subsection{Monitoring of Selected Lactobacilli Strains in Sourdough Fermentations}

A Randomly Amplified Polymorphic DNA (RAPD) analysis was performed according to Venturi et al. [34] to assess the occurrence of the selected lactobacilli in liquid and firm sourdoughs and final doughs. DNA was amplified using the following primers: OPL-05 (50 ACGCAGGCA 30), designed by Seseña et al. [35], and MV1 (50 GGACGCTTCTG 30) designed by Venturi et al. [34]. The random primer MV1 was used separately, while OPL-05 was used along with the primer RD1 ( $5^{\prime}$ GCTTAAGGAGGTGATCCAGCC 3'). DNA amplification was performed as described by Reguant 
and Bordons [36]. Amplification products were separated (at $100 \mathrm{~V}$ for $2.5 \mathrm{~h}$ ) on $1.4 \%(w / v)$ agarose gel (Lonza Group Ltd, Basel, Switzerland); containing ethidium bromide (Sigma e Aldrich, St Louis, MI, USA) and TEB buffer (1 M Tris, $10 \mathrm{mM}$ EDTA, $0.9 \mathrm{M}$ boric acid, $\mathrm{pH}$ 8.3). The resulting profiles were captured as images after UV transillumination, and compared to those previously obtained for each bacterial strain.

\subsection{Determination of $\mathrm{pH}$, Total Titratable Acidity, Volume Increase, and Enumeration of Cultivable Bacteria and Yeasts}

Ten grams of dough sample were transferred into $90 \mathrm{~mL}$ of sterile physiological solution, homogenized for $2 \mathrm{~min}$ in a Stomacher Lab Blender 400 (Seward Ltd, Worthing, West Sussex, $\mathrm{UK})$. After decimal dilutions, $100 \mu \mathrm{L}$ of these suspensions were plated for cell enumeration using MR3i medium for the lactobacilli and MYPG for the baker's yeast using the pour plate method. Lactobacilli were counted after incubation for $48-72 \mathrm{~h}$ at $30^{\circ} \mathrm{C}$ under anaerobic conditions. Yeasts, plated on MYPG agar containing sodium propionate $(2 \mathrm{~g} / \mathrm{L})$, were counted after incubation for $48 \mathrm{~h}$ at $30^{\circ} \mathrm{C}$ under aerobic conditions. Plate counts were performed in duplicate. The $\mathrm{pH}$ values were determined by a pH-meter (Metrohm Italiana Srl, Varese, Italy). Total titratable acidity (TTA) was measured on $10 \mathrm{~g}$ of dough samples, which were homogenized with $90 \mathrm{~mL}$ of distilled water for $3 \mathrm{~min}$ and expressed as the amount $(\mathrm{mL})$ of $0.1 \mathrm{~N} \mathrm{NaOH}$ to achieve a $\mathrm{pH}$ of 8.5 . To assess sourdough increase of volume, $100 \mathrm{~g}$ of each dough were placed in a graduated cylinder $(0.5 \mathrm{~L})$. The volume of the doughs (in $\mathrm{mL}$ ) was recorded immediately $\left(\mathrm{t}_{0}\right)$ and after $3 \mathrm{~h}$ of fermentation at $30{ }^{\circ} \mathrm{C}$. The leavening was calculated using the following formula: $\left(\left(\mathrm{V}_{3}-\mathrm{V}_{0}\right) / \mathrm{V}_{0}\right) \times 100$, where $\mathrm{V}_{3}$ was the volume after the $3 \mathrm{~h}$ fermentation and $\mathrm{V}_{0}$ was the initial volume.

\subsection{Determination of Lactic Acid by HPLC}

Bread samples were diluted ten times with distilled water and then filtered by Amicon ${ }^{\circledR}$ Ultra-4 Centrifugal Filters (3000 Da NMWL) (Merck Millipore) before the injection for lactic acid determination by high-performance liquid chromatography (HPLC) analysis (Varian Inc., Palo Alto, CA, USA) connected to a refractive index detector (Knauer K-2301, Knauer GmbH, Berlin, Germany) and UV detector $(\lambda=210)$. Elution was performed at $65^{\circ} \mathrm{C}$ with $0.01 \mathrm{~N} \mathrm{H}_{2} \mathrm{SO}_{4}$ eluent at a flow rate of $0.6 \mathrm{~mL} / \mathrm{min}$. Data were collected and analysed by using the Galaxie software (Varian Inc., Palo Alto, CA, USA). Quantitative analysis was carried out by a standard curve.

\subsection{Total Phenols Assay by Folin-Ciocalteau Reagent}

Total phenols content of bread samples was determined according to Alvarez-Jubete et al. [37], with some modifications. Bread samples were dried for $24 \mathrm{~h}$ at $60{ }^{\circ} \mathrm{C}$ and ground. $1.25 \mathrm{~g}$ were weighted and added to $25 \mathrm{~mL}$ methanol. Samples were vortexed and left in horizontal shaking for $24 \mathrm{~h}$, then centrifuged for $10 \mathrm{~min}$ at $2000 \times \mathrm{g}$. The final extracts were obtained by filtering $10 \mathrm{~mL}$ of the supernatant through $0.22 \mu \mathrm{m}$ PTFE syringe filters (Whatman) and they were stored at $-20{ }^{\circ} \mathrm{C}$ until analysis. The reaction mixture consisted of $100 \mu \mathrm{L}$ of methanolic bread extract, $100 \mu \mathrm{L}$ of methanol, 100 $\mu \mathrm{L}$ of Folin-Ciocalteu reagent and $700 \mu \mathrm{L}$ of $\mathrm{Na}_{2} \mathrm{CO}_{3}$. The samples were vortexed immediately, and the tubes were incubated in the dark for $20 \mathrm{~min}$ at room temperature. After incubation, all samples were centrifuged at $11,300 \times g$ for $3 \mathrm{~min}$. The absorbance of the supernatant was then measured at $735 \mathrm{~nm}$ in $1 \mathrm{~mL}$ plastic cuvette using a spectrophotometer (Cary 50 Scan, Varian Inc., Palo Alto, CA, USA). Gallic acid was used as a standard and a calibration curve was prepared with a range of concentrations from $10-200 \mathrm{mg} / \mathrm{L}$. The results are expressed in $\mathrm{mg}$ of gallic acid equivalent per $100 \mathrm{~g}$ of dry-weight basis (mg GAE $100 \mathrm{~g}^{-1} \mathrm{dwb}$ ).

\subsection{Antioxidant Capacity by DPPH Assay}

The free radical scavenging capacity of methanolic bread extracts was determined using the stable 2,2-diphenyl-1-picrylhydrazyl radical (DPPH). The scavenging effect was measured according to the 
method of Alvarez-Jubete et al. [37]. Also, $500 \mu \mathrm{L}$ of extracts were added to $500 \mu \mathrm{L}$ of DPPH methanolic solution $(0.05 \mathrm{mg} / \mathrm{mL})$. After vortexing, the mixture was left for $40 \mathrm{~min}$ at room temperature, and the absorbance of the resulting solution was read at $517 \mathrm{~nm}$. The absorbance measured after $40 \mathrm{~min}$ was used for the calculation of the antioxidant capacity according to the following formula: DPPH radical-scavenging activity (\%): ((blank absorbance - sample absorbance)/blank absorbance $) \times 100$. Butylated hydroxytoluene (BHT) was also assayed as antioxidant references.

\subsection{HPLC Determination of GABA Content}

GABA content was determined on the water-soluble extracts of liquid doughs and breads. The extracts were obtained by extracting the samples with sterile distilled water $(1: 3 w / v)$, held at $4{ }^{\circ} \mathrm{C}$ for $1 \mathrm{~h}$ and vortexed at 15 -min intervals. Samples were finally centrifuged at $14,000 \times \mathrm{g}$ for $20 \mathrm{~min}$. The supernatants, containing the water-soluble fraction, were used for GABA quantification. Before the injection, the samples were prepared according to Tuberoso et al. [38]. The reaction mixture consisted of $100 \mu \mathrm{L}$ of sample extracts, $5 \mu \mathrm{L}$ of $100 \mathrm{mg} / \mathrm{L}$ eptilammine (internal standard, IS), $200 \mu \mathrm{L}$ of dansyl chloride solution (derivatization agent) and $0.2 \mathrm{M} \mathrm{Na}_{2} \mathrm{~B}_{4} \mathrm{O}_{7} \cdot 10 \mathrm{H}_{2} \mathrm{O}(\mathrm{pH}$ 9.3) solution up to a final volume of $1000 \mu \mathrm{L}$. The mixture was incubated for $30 \mathrm{~min}$ at $40{ }^{\circ} \mathrm{C}$ in a Termoblok and centrifuged at $11,300 \times g$ for $10 \mathrm{~min}$. The supernatant was recovered and diluted with $\mathrm{MeOH}(1: 1$ $v / v)$ for HPLC analysis. Separation was obtained with a Phenomenex Gemini C18 110A column (150 $4.60 \mathrm{~mm}, 3 \mathrm{~lm}$; Chemtek Analitica, Anzola Emilia, Bologna, Italy) connected to fluorimetric detector (Jasco Europe, Cremella, LC, Italy) with wavelengths set at $293 \mathrm{~nm}$ (Ex) and $492 \mathrm{~nm}$ (Em) under the following conditions: Mobile phases buffer acetate/ $\mathrm{CH}_{3} \mathrm{CN}(\mathrm{pH} 4.1)$ and acetonitrile, flow rate $0.8 \mathrm{~mL} / \mathrm{min}$, column temperature $25^{\circ} \mathrm{C}$. The quantitative analysis was performed using calibration graphs constructed according to the internal standard method.

\subsection{Sensory Evaluation}

Sensory evaluation of lactobacilli inoculated breads and non-acidified control breads was carried out by 46 panellists ( 15 male and 31 female) aged 21-65 years old. Breads were cut into pieces of $3 \mathrm{~cm} \times 3 \mathrm{~cm}$ and randomly codified before serving. Colour, aroma, consistency, and general liking were evaluated using the hedonic 9-point scale (from "1-dislike extremely" to "9-like extremely") [39]. Panellists have also optionally chosen among 13 attributes for the taste of breads: Salty, vapid, sweet, earthy, strange taste, sour, delicate, tasty, astringent, not to eat, gummy, interesting, and persistent [24].

\subsection{Statistical Analysis}

Chemical and microbiological determinations, performed in duplicate, were elaborated according to $t$-Test procedures or nonparametric one-way ANOVA followed by Tukey's Test (Statistica 7.0 software package, Stat Software Inc., Tulsa, OK, USA). Differences were reported at a significance level of $p \leq 0.05$.

\section{Results and Discussion}

\subsection{Selection of GABA-Producing Lactobacilli Strains}

Eighteen lactobacilli strains were singly inoculated in liquid doughs made with either wheat or amaranth flour and incubated at $30^{\circ} \mathrm{C}$ for $6 \mathrm{~h}$ in order to evaluate the GABA production. All the strains were able to acidify the doughs although some differences were registered. The final $\mathrm{pH}$ values ranged from ca 3.50-4.10 with an average decrease of $2.35 \pm 0.13$ in wheat sourdoughs. Due to the lower flour content $(\mathrm{DY}=667)$ and a different buffering capacity, the final $\mathrm{pH}$ of amaranth sourdoughs resulted higher, in a range from $4.10-5.10$, with an average $\mathrm{pH}$ decrease of $1.74 \pm 0.41$. The most acidifying strains, both in wheat and amaranth flour, were L. brevis A7, L. farciminis A11, L. farciminis $\mathrm{B} 7$ and L. rossiae Ga12. The values of $\mathrm{pH}$ of the non-inoculated doughs (C) were $5.96 \pm 0.05$ and $6.20 \pm 0.11$ for wheat and amaranth dough, respectively. After $6 \mathrm{~h}$ of fermentation GABA concentrations were determined. 
Results showed a variability $(p \leq 0.05)$ among the tested strains in both the flours, even if GABA concentrations were generally higher in wheat sourdoughs (Figure 1). Differences in GABA concentration in sourdoughs produced by the two flours could be due to higher glutamic acid content in wheat flour, since it is the substrate for glutamic acid decarboxylase enzyme (GAD). In agreement with the literature, the GABA producing activity was not related to the species, resulting in strain dependency [40]. In wheat sourdoughs, six lactobacilli strains displayed GABA concentrations significantly higher than the control and the acidified control, whereas in amaranth sourdoughs this trend was observed only for one strain (L. rossiae Gd63). Particularly, the highest ( $p \leq 0.05)$ GABA concentration in wheat sourdoughs was found in the dough inoculated with L. brevis A7 $(136.62 \pm 4.00 \mathrm{mg} / \mathrm{kg}$ of flour), followed by L. plantarum $\mathrm{O} 4$, L. brevis Ga1, L. farciminis $\mathrm{H} 3$, L. rossiae O1, L. farciminis A11. The strain L. rossiae Gd63 displayed the highest GABA production in amaranth sourdough fermentation ( $47.6 \pm 14.3 \mathrm{mg} / \mathrm{kg}$ of flour), although other six lactobacilli strains (L. plantarum C2, L. brevis A7, L. sanfranciscensis Gd44, L. brevis B1, L. rossiae Ga14 and L. farciminis A11) did not show statistical differences from the GABA amounts produced by the best performing strain. Hence, based on the reported results concerning GABA production and acidification ability, L. farciminis A11 and $L$. brevis A7 were selected to prepare firm sourdoughs and breads.

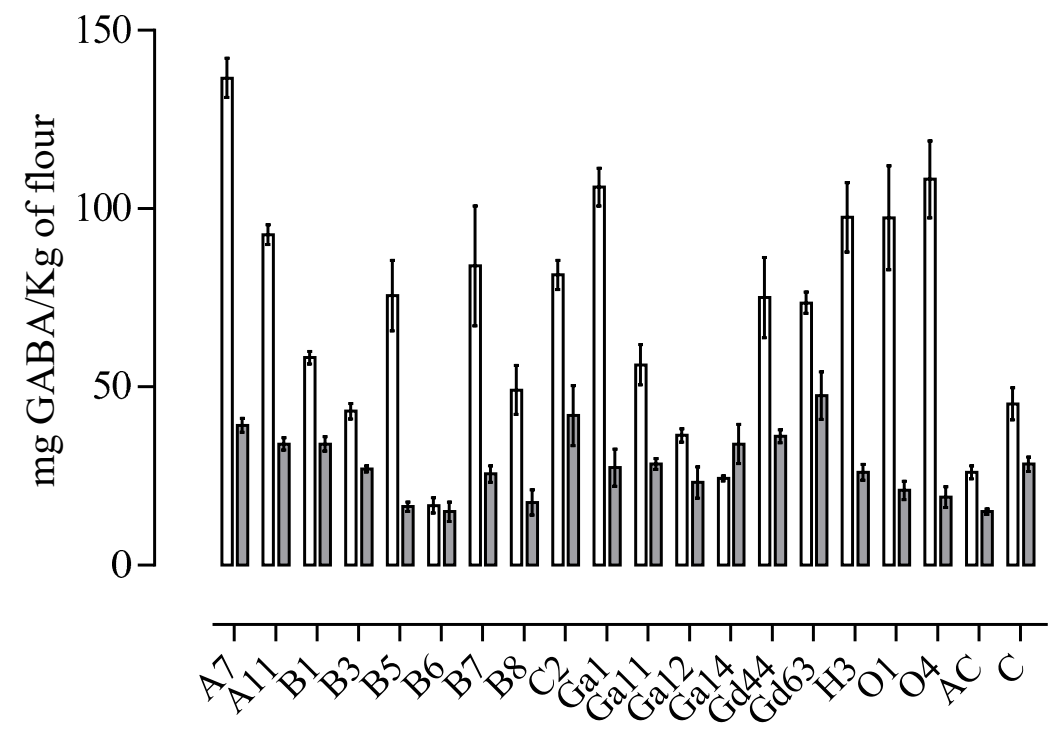

Figure 1. Production of GABA after $6 \mathrm{~h}$ fermentation in wheat (white bar) and amaranth (grey bar) sourdoughs obtained with 18 lactobacilli strains singly inoculated (data are expressed as mean \pm coefficient of variation \%). C-control; AC-acid control.

\subsection{Sourdough Bread Fermentation with Selected Lactobacilli Strains}

Breads were prepared with the addition of $20 \%$ of amaranth flour. This percentage was chosen because it is considered appropriate by various authors in order to maintain product structural quality [41], preserve the principal nutritional benefit of this ingredient [42], and meet sensory approval [43]. Table 3 shows the main technological and microbiological characteristics at the end of fermentation of the sourdoughs prepared with the inoculum of L. brevis A7 (SD-A7) and L. farciminis A11 (SD-A11). The occurrence of the two inoculated strains throughout the process was confirmed by molecular analysis. In particular, all the lactobacilli isolates from sourdoughs displayed solely the genotypic patterns of L. brevis A7 or L. farciminis A11. 
Table 3. Values (mean \pm standard deviation) of $\mathrm{pH}$, Total Titratable Acidity (TTA; $\mathrm{mL} \mathrm{NaOH}$ ), lactic acid $(\mathrm{g} / \mathrm{kg})$, volume increase $(\%)$, and microorganism (lactobacilli and baker's yeast) concentrations (log (CFU/g)) after sourdough fermentations carried out by L. brevis A7 (SD-A7) and L. farciminis A11 (SD-A11).

\begin{tabular}{ccccccccc}
\hline Dough & Final $\mathbf{p H}$ & $\mathbf{\Delta} \mathbf{p H}$ & Final TTA & $\Delta$ TTA & Lactic acid & $\Delta \mathbf{V} / \mathbf{V} \mathbf{0} \times \mathbf{1 0 0}$ & Lactobacilli & Yeasts \\
\hline SD-A7 & $4.35 \pm 0.03^{\mathrm{a}}$ & $0.95 \pm 0.39^{\mathrm{a}}$ & $6.90 \pm 0.14^{\mathrm{b}}$ & $2.80 \pm 0.66^{\mathrm{a}}$ & $4.60 \pm 0.63^{\mathrm{b}}$ & $105 \pm 7.07^{\mathrm{a}}$ & $8.50 \pm 0.72^{\mathrm{a}}$ & $7.35 \pm 0.64^{\mathrm{a}}$ \\
SD-A11 & $4.60 \pm 0.18^{\mathrm{b}}$ & $0.82 \pm 0.10^{\mathrm{a}}$ & $6.45 \pm 0.07^{\mathrm{a}}$ & $2.95 \pm 0.78^{\mathrm{a}}$ & $3.20 \pm 0.56^{\mathrm{a}}$ & $105 \pm 21.2^{\mathrm{a}}$ & $8.59 \pm 0.73^{\mathrm{a}}$ & $7.40 \pm 0.62^{\mathrm{a}}$ \\
\hline
\end{tabular}

$\Delta \mathrm{V}=$ difference between the final and the initial value; $\mathrm{V}_{0}$-initial volume. Values in the same column with different letters $(\mathbf{a}, \mathbf{b})$ are significantly different $(p \leq 0.05)$.

The 20\% amaranth incorporation did not affect the considered features. At the end of leavening time, both the sourdough $\mathrm{pH}$ decreased of about 0.88 , reaching a value of $4.35 \pm 0.03$ for SD-A7 and $4.60 \pm 0.18$ for SD-A11, statistically different from each other and showing proper acidification $[44,45]$. SD-A11 final total titratable acidity was lower compared to SD-A7, while the TTA increase did not point out any significant differences. Regarding organic acids production, the highest content of lactic acid was found in SD-A7 dough $(4.60 \pm 0.63 \mathrm{~g} / \mathrm{kg})$. Both the samples doubled their volume, indicating an adequate leavening process. Microbiological analyses did not show any significant differences in the microorganism concentrations at the end of the fermentation. L. farciminis A11 and L. brevis A7 reached a concentration of about $8.55 \log \mathrm{CFU} / \mathrm{g}$, which is a typical value in sourdough [46], and $S$. cerevisiae reached a concentration of $7.37 \log \mathrm{CFU} / \mathrm{g}$.

\subsection{Phenolic Content and Antioxidant Capacity of Breads}

The results of the total phenolic content, determined on the methanolic extracts of all the breads, are shown in Figure 2.

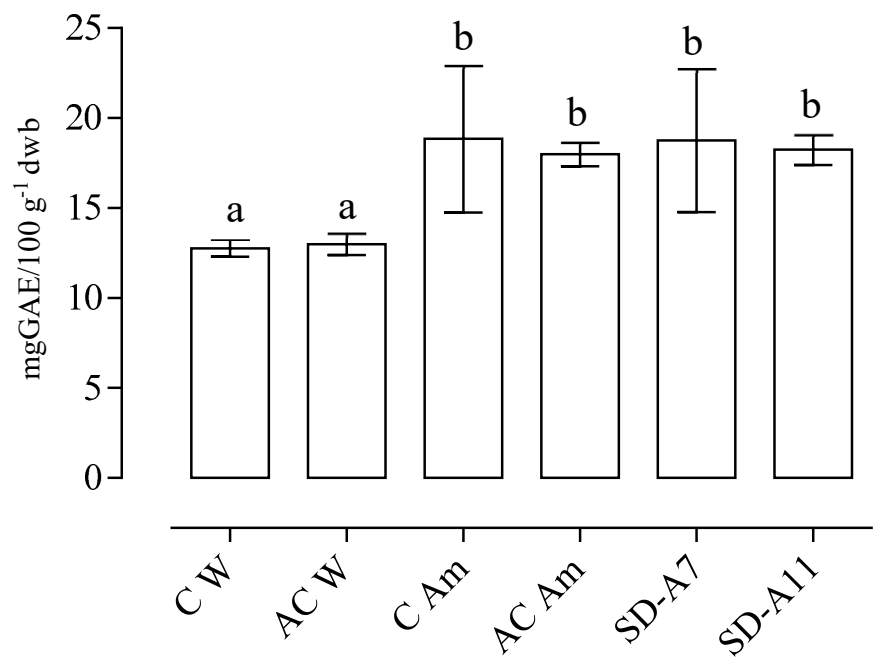

Figure 2. Total phenolic content (expressed as mg of gallic acid equivalents GAE100 $\mathrm{g}^{-1} \mathrm{dwb}$ ) of the breads (data are expressed as mean \pm coefficient of variation \%). C W-wheat control bread; AC W-wheat acid control bread; C Am—amaranth control bread; AC Am-amaranth acid control bread; SD-A7-L. brevis A7 bread; SD-A11—L. farciminis A11 bread. Different letters (a,b) indicate significant differences $(p \leq 0.05)$.

Results indicated that amaranth flour addition significantly increased the phenolic content of breads. Indeed, whole pseudocereal grains are rich in this class of minor components, therefore their use as a supplement can increase the nutritional value of baked goods. Data showed that samples integrated with $20 \%$ of amaranth flour displayed a phenolic content of more than $15 \mathrm{mg}$ GAE $100 \mathrm{~g}^{-1}$ $\mathrm{dwb}$, which was significantly higher than the control breads, C W and AC W, made only with wheat flour $(p \leq 0.05)$. These results are in agreement with those reported by Chlopicka et al. [24], which 
showed a higher content of phenolic compounds in breads enriched with amaranth flour, compared to a control bread without this pseudocereal addition.

The radical-scavenging capacity of the breads was tested by the DPPH method (Figure 3).

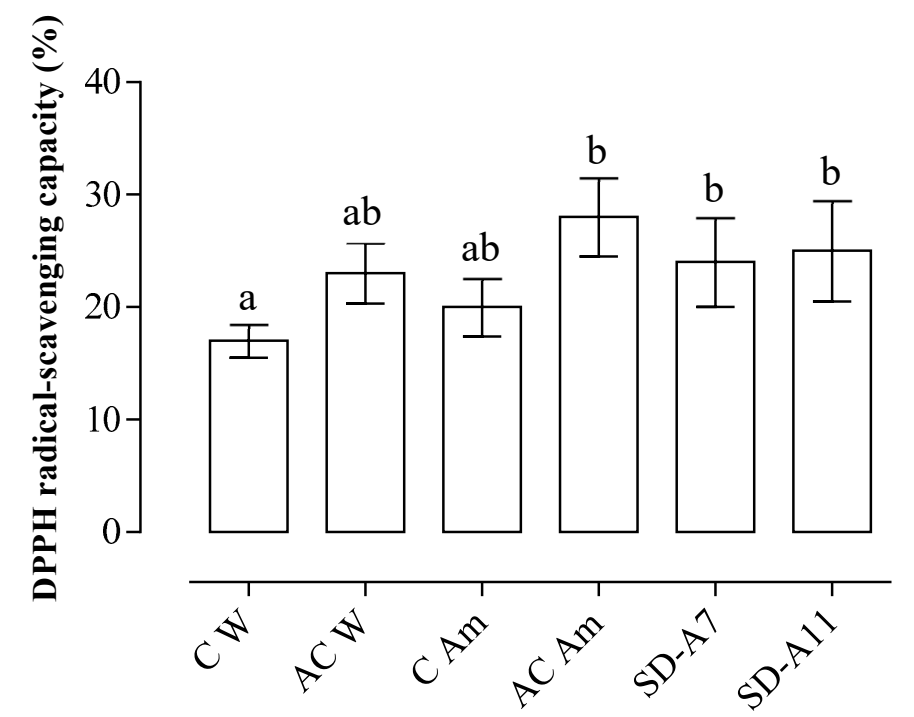

Figure 3. Radical-scavenging capacity (\%) of the breads (data are expressed as mean \pm coefficient of variation \%). C W-wheat control bread; AC W-wheat acid control bread; C Am-amaranth control bread; AC Am—amaranth acid control bread; SD-A7—L. brevis A7 bread; SD-A11—L. farciminis A11 bread. Different letters (a,b) indicate significant differences $(p \leq 0.05)$.

The antioxidant capacity of control bread made with only wheat flour result was the lowest among the samples (less than 17\%), while AC Am, SD-A7 and SD-A11 showed the highest values $(p \leq 0.05)$, up to $28 \%$. According to Vollmannova et al. [47], total phenolic content was partially correlated to the antioxidant capacity; indeed, AC Am, SD-A7 and SD-A11 showed the highest values for both these parameters. Amaranth addition only slightly increased the antioxidant capacity, on the contrary, the acidification seems to have a higher role in increasing this activity. In fact, both the chemically acidified controls showed higher values than the controls. Hence, the combination of amaranth addition and acidification might be responsible of the observed phenomenon. In this context, it was demonstrated that acidification, as a consequence of microbial fermentation, can increase the levels of easily-extractable phenolic compounds and their bioavailability $[4,48,49]$.

\subsection{GABA Content of Breads}

GABA concentrations in the breads prepared by lactobacilli inoculated sourdoughs and in the control breads are reported in Figure 4.

GABA content in the breads ranged from $8.0-39.0 \mathrm{mg} / \mathrm{kg}$. Sourdough breads showed the highest concentration with values of $26.9 \pm 1.53$ and $39.0 \pm 1.53 \mathrm{mg} / \mathrm{kg}$ for SD-A7 and SD-A11, respectively, confirming the capability of LAB to produce GABA. The lowest content was detected in the control breads with $100 \%$ of wheat flour, less than $10 \mathrm{mg} / \mathrm{kg}$. Compared to the control wheat breads, the GABA increase of SD-A11 was of about $350 \%$. Other studies exploited high GABA producing biotype of Lactobacillus plantarum and Lactococcus lactis in order to obtain a bread with improved nutritional features $[10,18,19]$. The ability of $L$. brevis strains to synthetize GABA was reported in various food matrices such as cheese [40], yoghurt [50], black raspberry juice [51], and wheat sourdough [11], while this capability was observed only in a strain of L. farciminis isolated from Myanmar traditional fermented fishery products with boiled rice [52]. To the best of our knowledge, this was the first time in which GABA production by a strains of L. farciminis was exploited in a bakery product. 


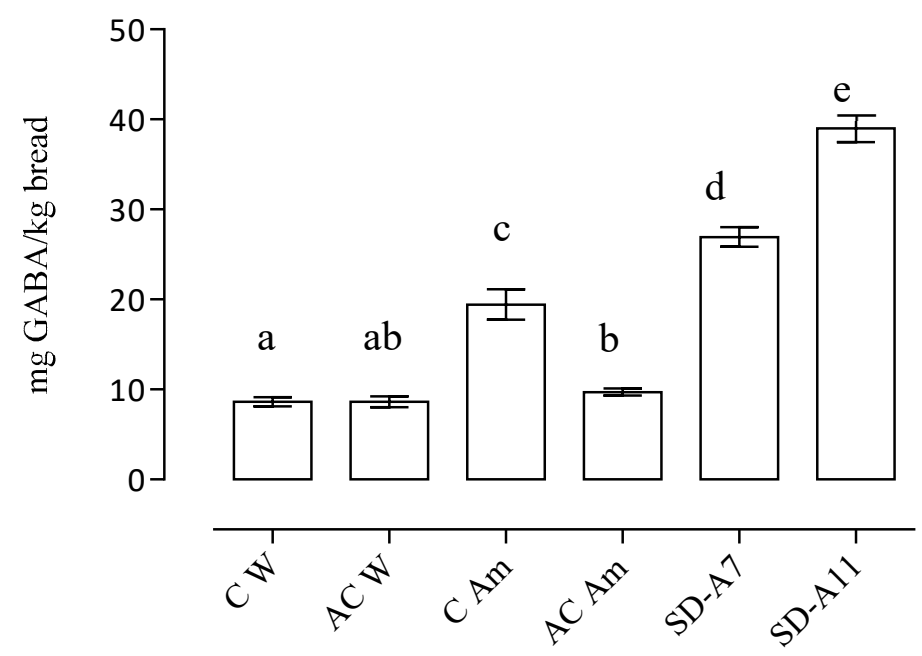

Figure 4. GABA concentration $(\mathrm{mg} / \mathrm{kg}$ ) in the breads (data are expressed as mean \pm standard deviation). $\mathrm{C}$ W-wheat control bread; AC W-wheat acid control bread; C Am-amaranth control bread; AC Am-amaranth acid control bread; SD-A7—L. brevis A7 bread; SD-A11-L. farciminis A11 bread. Different letters $(\mathbf{a}-\mathbf{c})$ indicate significant differences $(p \leq 0.05)$.

\subsection{Sensory Evaluation}

To evaluate the contribution of amaranth flour and lactobacilli fermentation on organoleptic characteristics of breads, a sensory evaluation was carried out with a panel of 46 members. Table 4 shows the results of a 9-point hedonic scale analysis of colour, odour, consistency, and general liking.

Table 4. Sensory evaluation of breads (mean \pm standard deviation). Values were determined with a 9-point scale (extremely disliked $=1$, neither like, nor dislike $=5$, extremely liked $=9$ ). $\mathrm{C} \mathrm{W-wheat}$ control bread; C Am-amaranth control bread; SD-A7—L. brevis A7 bread; SD-A11—L. farciminis A11 bread.

\begin{tabular}{ccccc}
\hline & C W & C Am & SD-A7 & SD-A11 \\
\hline Colour & $6.7 \pm 1.3^{\mathrm{a}}$ & $6.2 \pm 1.2^{\mathrm{a}}$ & $6.1 \pm 1.2^{\mathrm{a}}$ & $6.0 \pm 1.5^{\mathrm{a}}$ \\
Aroma & $6.1 \pm 1.5^{\mathrm{a}}$ & $5.6 \pm 1.6^{\mathrm{a}}$ & $5.6 \pm 1.5^{\mathrm{a}}$ & $5.3 \pm 2.0^{\mathrm{a}}$ \\
Consistency & $6.3 \pm 1.4^{\mathrm{b}}$ & $5.8 \pm 1.6^{\mathrm{ab}}$ & $5.1 \pm 1.6^{\mathrm{a}}$ & $5.2 \pm 1.5^{\mathrm{a}}$ \\
General liking & $6.3 \pm 1.5^{\mathrm{b}}$ & $5.3 \pm 1.6^{\mathrm{a}}$ & $4.9 \pm 1.6^{\mathrm{a}}$ & $4.9 \pm 1.8^{\mathrm{a}}$ \\
\hline \multicolumn{7}{l}{ Values in the same column with different letters $(\mathbf{a}, \mathrm{b})$ are significantly different $(p \leq 0.05)}$.
\end{tabular}

Values of colour and aroma were not significantly different among the breads, ranging from 6-6.7 and from 5.3-6.1, hence indicating a moderate appreciation. On the contrary, the consistency of bread was negatively affected by the addition of amaranth flour; in fact, the best value was registered for the control wheat bread $(6.3 \pm 1.4)$, statistically higher $(p \leq 0.05)$ compared to the inoculated amaranth breads (5.1-5.2). General liking of the $100 \%$ wheat control bread showed a significantly higher value $(6.3 \pm 1.5)$ compared to bread with amaranth replacement; however, none of the breads were negatively evaluated by the panellists. These results pointed out that substituting $20 \%$ of wheat flour with amaranth flour in bread was not advantageous for bread sensory evaluation, even if the panellists gave a moderate appreciation. In addition, other authors [42] reported that, considering the better nutritional features, consumers would choose to consume amaranth bread instead of common wheat bread, even if the taste is different. Furthermore, the spider plot in Figure 5 shows the different attributes chosen by panellists to describe breads. 


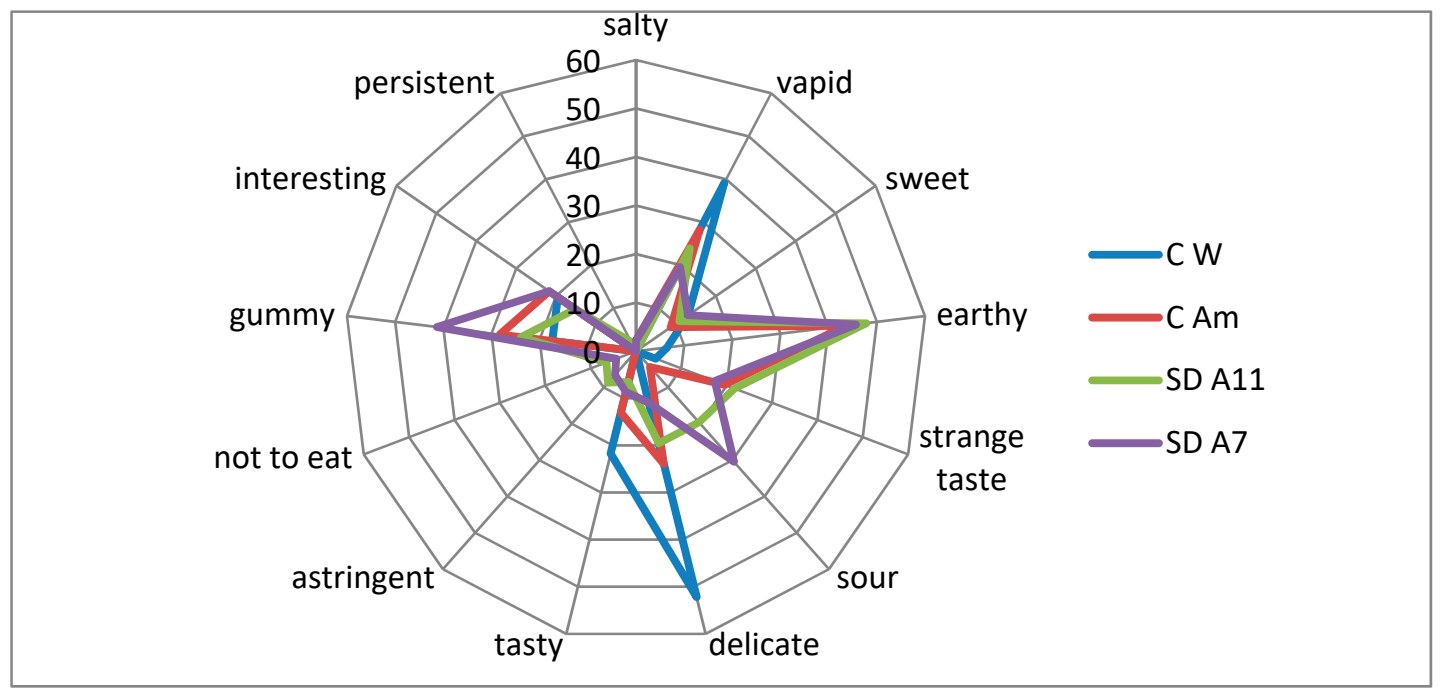

Figure 5. Spider plot of the sensory evaluation (\%) of breads. Blue line: $\%$ of positive answers given to wheat control bread (C W); red line: \% of positive answers given to amaranth control bread (C Am); green line: \% of positive answers given to L. farciminis A11 sourdough bread (SD-A11); purple line: \% of positive answers given to L. brevis A7 sourdough bread (SD-A7).

Amaranth clearly characterized bread for earthy taste (about $50 \%$ panellists for all the amaranth breads). More than $50 \%$ panellists defined the wheat control bread as delicate, even if $40 \%$ also defined breads as vapid with respect to $20-30 \%$ of the breads with amaranth. In particular, panellists declared that SD-A7 bread was sour (30\%) and gummy (more than $40 \%$ ). Nevertheless, about $20 \%$ of panellists described as interesting the taste of all the breads, and only a few testers (about $5 \%$ ) declared SD amaranth breads "not to eat", in contrast with the 10-30\% reported in other experiments [24]. Sensory analysis highlighted some differences between the two sourdough amaranth breads. SD-A7 bread taste was described as less delicate, gummier, and sourer, but also more interesting compared to SD-A11 bread. However, results showed that the $20 \%$ amaranth incorporation did not strongly reduce the breads' appreciation.

\section{Conclusions}

The screening of GABA-producing lactobacilli in liquid sourdoughs led to the selection of two strains belonging to L. farciminis and L. brevis species. These strains were able to increase GABA concentration (up to $350 \%$ ) in breads enriched with $20 \%$ of amaranth flour, with a final content of $26.9 \pm 1.53$ and $39.0 \pm 1.53 \mathrm{mg} / \mathrm{kg}$ respectively. The final products showed higher antioxidant activity and an increased content of total phenolic compounds compared to the wheat control bread. Sensory evaluation indicated moderate acceptability of breads with amaranth flour, mainly characterized by an earthy taste. Although organoleptic acceptability of the final products could be improved, the combination of selected lactobacilli and pseudocereal flours can be a suitable tool for the production of innovative baked goods with improved nutritional features.

Author Contributions: Conceptualization, M.V. and V.G.; methodology, M.V. and V.G.; formal analysis, M.V., V.G. and N.P.; investigation, M.V., V.G. and N.P.; data curation, M.V., V.G. and L.G.; writing-original draft preparation, M.V. and V.G; writing-review and editing, M.V., V.G., S.G. and L.G.; supervision, S.G. and L.G.

Funding: This research received no external funding.

Conflicts of Interest: The authors declare no conflict of interest. 


\section{References}

1. Chavan, R.S.; Chavan, S.R. Sourdough technology-A traditional way for wholesome foods: A review. Compr. Rev. Food Sci. Food Saf. 2011, 10, 169-182. [CrossRef]

2. Arendt, E.K.; Ryan, L.A.; Dal Bello, F. Impact of sourdough on the texture of bread. Food Microbiol. 2007, 24, 165-174. [CrossRef] [PubMed]

3. Hammes, W.P.; Gänzle, M.G. Sourdough breads and related products. In Microbiology of Fermented Foods, 2nd ed.; Woods, B.J.B., Ed.; Blackie Academic: London, UK, 1998; pp. 199-216.

4. Gobbetti, M.; De Angelis, M.; Di Cagno, R.; Calasso, M.; Archetti, G.; Rizzello, C.G. Novel insights on the functional/nutritional features of the sourdough fermentation. Int. J. Food Microbiol. 2018. [CrossRef] [PubMed]

5. Diana, M.; Quílez, J.; Rafecas, M. Gamma-aminobutyric acid as a bioactive compound in foods: A review. J. Funct. Foods 2014, 10, 407-420. [CrossRef]

6. Di Cagno, R.; De Angelis, M.; Lavermicocca, P.; De Vincenzi, M.; Giovannini, C.; Faccia, M.; Gobbetti, M. Proteolysis by sourdough lactic acid bacteria: Effects on wheat flour protein fractions and gliadin peptides involved in human cereal intolerance. Appl. Environ. Microbiol. 2002, 68, 623-633. [CrossRef]

7. Gänzle, M.G.; Loponen, J.; Gobbetti, M. Proteolysis in sourdough fermentations: Mechanisms and potential for improved bread quality. Trends Food Sci. Technol. 2008, 19, 513-521. [CrossRef]

8. Gobbetti, M.; Rizzello, C.G.; Di Cagno, R.; De Angelis, M. How the sourdough may affect the functional features of leavened baked goods. Food Microbiol. 2014, 37, 30-40. [CrossRef]

9. Paterson, A.; Piggott, J.R. Flavour in sourdough breads: A review. Trends Food Sci. Technol. 2006, 17, 557-566. [CrossRef]

10. Bhanwar, S.; Bamnia, M.; Ghosh, M.; Ganguli, A. Use of Lactococcus lactis to enrich sourdough bread with $\gamma$-aminobutyric acid. Int. J. Food Sci. Nutr. 2013, 64, 77-81. [CrossRef]

11. Diana, M.; Rafecas, M.; Quílez, J. Free amino acids, acrylamide and biogenic amines in gamma-aminobutyric acid enriched sourdough and commercial breads. J. Cereal Sci. 2014, 60, 639-644. [CrossRef]

12. Huang, J.; Mei, L.H.; Wu, H.; Lin, D.Q. Biosynthesis of $\gamma$-aminobutyric acid (GABA) using immobilized whole cells of Lactobacillus brevis. World J. Microbiol. Biot. 2007, 23, 865-871. [CrossRef]

13. Komatsuzaki, N.; Shima, J.; Kawamoto, S.; Momose, H.; Kimura, T. Production of $\gamma$-aminobutyric acid (GABA) by Lactobacillus paracasei isolated from traditional fermented foods. Food Microbiol. 2005, 22, 497-504. [CrossRef]

14. Komatsuzaki, N.; Tsukahara, K.; Toyoshima, H.; Suzuki, T.; Shimizu, N.; Kimura, T. Effect of soaking and gaseous treatment on GABA content in germinated brown rice. J. Food Eng. 2007, 78, 556-560. [CrossRef]

15. Su, Y.C.; Wang, J.J.; Lin, T.T.; Pan, T.M. Production of the secondary metabolites $\gamma$-aminobutyric acid and monacolin K by Monascus. J. Ind. Microbiol. Biot. 2003, 30, 41-46. [CrossRef] [PubMed]

16. Okada, T.; Sugishita, T.; Murakami, T.; Murai, H.; Saikusa, T.; Horino, T.; Onoda, A.; Kajimoto, O.; Takahashi, R.; Takahashi, T. Effect of the defatted rice germ enriched with GABA for sleeplessness, depression, autonomic disorder by oral administration. J. Jpn. Soc. Food Sci. 2000, 47, 596-603. [CrossRef]

17. Ueno, H. Enzymatic and structural aspects on glutamate decarboxylase. J. Mol. Catal. B-Enzym. 2000, 10, 67-79. [CrossRef]

18. Coda, R.; Rizzello, C.G.; Gobbetti, M. Use of sourdough fermentation and pseudo-cereals and leguminous flours for the making of a functional bread enriched of $\gamma$-aminobutyric acid (GABA). Int. J. Food Microbiol. 2010, 137, 236-245. [CrossRef] [PubMed]

19. Rizzello, C.G.; Cassone, A.; Di Cagno, R.; Gobbetti, M. Synthesis of angiotensin I-converting enzyme (ACE)-inhibitory peptides and $\gamma$-aminobutyric acid (GABA) during sourdough fermentation by selected lactic acid bacteria. J. Agric. Food Chem. 2008, 56, 6936-6943. [CrossRef]

20. Villegas, J.M.; Brown, L.; de Giori, G.S.; Hebert, E.M. Optimization of batch culture conditions for GABA production by Lactobacillus brevis CRL 1942, isolated from quinoa sourdough. LWT-Food Sci. Technol. 2016, 67, 22-26. [CrossRef]

21. Lamberts, L.; Joye, I.J.; Beliën, T.; Delcour, J.A. Dynamics of $\gamma$-aminobutyric acid in wheat flour bread making. Food Chem. 2012, 130, 896-901. [CrossRef]

22. Coda, R.; Di Cagno, R.; Gobbetti, M.; Rizzello, C.G. Sourdough lactic acid bacteria: Exploration of non-wheat cereal-based fermentation. Food Microbiol. 2014, 37, 51-58. [CrossRef] [PubMed] 
23. Schoenlechner, R.; Siebenhandl, S.; Berghofer, E. Pseudocereals. In Gluten-Free Cereal Products and Beverages, 1st ed.; Arendt, E.K., Dal Bello, F., Eds.; Academic Press: New York, NY, USA, 2008; p. 149-VI.

24. Chlopicka, J.; Pasko, P.; Gorinstein, S.; Jedryas, A.; Zagrodzki, P. Total phenolic and total flavonoid content, antioxidant activity and sensory evaluation of pseudocereal breads. LWT-Food Sci. Technol. 2012, 46, 548-555. [CrossRef]

25. Gorinstein, S.; Vargas, O.J.M.; Jaramillo, N.O.; Salas, I.A.; Ayala, A.L.M.; Arancibia-Avila, P.; Toledo, F.; Katrich, E.; Trakhtenberg, S. The total polyphenols and the antioxidant potentials of some selected cereals and pseudocereals. Eur. Food Res. Technol. 2007, 225, 321-328. [CrossRef]

26. Kalinova, J.; Dadakova, E. Rutin and total quercetin content in amaranth (Amaranthus spp.). Plant. Food. Hum. Nutr. 2009, 64, 68. [CrossRef]

27. Li, S.Q.; Zhang, Q.H. Advances in the development of functional foods from buckwheat. Crit. Rev. Food Sci. 2001, 41, 451-464. [CrossRef]

28. Lin, L.Y.; Liu, H.M.; Yu, Y.W.; Lin, S.D.; Mau, J.L. Quality and antioxidant property of buckwheat enhanced wheat bread. Food Chem. 2009, 112, 987-991. [CrossRef]

29. Paśko, P.; Sajewicz, M.; Gorinstein, S.; Zachwieja, Z. Analysis of selected phenolic acids and flavonoids in Amaranthus cruentus and Chenopodium quinoa seeds and sprouts by HPLC. Acta Chromatogr. 2008, 20, 661-672. [CrossRef]

30. Richardson, D.P. Wholegrain health claims in Europe. Proc. Nutr. Soc. 2003, 62, 161-169. [CrossRef]

31. Nimbalkar, M.S.; Pai, S.R.; Pawar, N.V.; Oulkar, D.; Dixit, G.B. Free amino acid profiling in grain Amaranth using LC-MS/MS. Food Chem. 2012, 134, 2565-2569. [CrossRef]

32. Jekle, M.; Houben, A.; Mitzscherling, M.; Becker, T. Effects of selected lactic acid bacteria on the characteristics of amaranth sourdough. J. Sci. Food Agric. 2010, 90, 2326-2332. [CrossRef]

33. Galli, V.; Venturi, M.; Pini, N.; Guerrini, S.; Granchi, L.; Vincenzini, M. Liquid and firm sourdough fermentation: Microbial robustness and interactions during consecutive backsloppings. LWT-Food Sci. Technol. 2019, 105, 9-15. [CrossRef]

34. Venturi, M.; Guerrini, S.; Granchi, L.; Vincenzini, M. Typing of Lactobacillus sanfranciscensis isolates from traditional sourdoughs by combining conventional and multiplex RAPD-PCR profiles. Int. J. Food Microbiol. 2012, 156, 122-126. [CrossRef] [PubMed]

35. Seseña, S.; Sánchez, I.; Palop, L. Characterization of Lactobacillus strains and monitoring by RAPD-PCR in controlled fermentations of "Almagro" eggplants. Int. J. Food Microbiol. 2005, 104, 325-335. [CrossRef]

36. Reguant, C.; Bordons, A. Typification of Oenococcus oeni strains by multiplex RAPD-PCR and study of population dynamics during malolactic fermentation. J. Appl. Microbiol. 2003, 95, 344-353. [CrossRef] [PubMed]

37. Alvarez-Jubete, L.; Wijngaard, H.; Arendt, E.K.; Gallagher, E. Polyphenol composition and in vitro antioxidant activity of amaranth, quinoa buckwheat and wheat as affected by sprouting and baking. Food Chem. 2010, 119, 770-778. [CrossRef]

38. Tuberoso, C.I.G.; Congiu, F.; Serreli, G.; Mameli, S. Determination of dansylated amino acids and biogenic amines in Cannonau and Vermentino wines by HPLC-FLD. Food Chem. 2015, 175, 29-35. [CrossRef] [PubMed]

39. Corona, O.; Alfonzo, A.; Ventimiglia, G.; Nasca, A.; Francesca, N.; Martorana, A.; Moschetti, G.; Settanni, L. Industrial application of selected lactic acid bacteria isolated from local semolinas for typical sourdough bread production. Food Microbial. 2016, 59, 43-56. [CrossRef]

40. Siragusa, S.; De Angelis, M.; Di Cagno, R.; Rizzello, C.G.; Coda, R.; Gobbetti, M. Synthesis of $\gamma$-aminobutyric acid by lactic acid bacteria isolated from a variety of Italian cheeses. Appl. Environ. Microbiol. 2007, 73, 7283-7290. [CrossRef]

41. Ayo, J.A. The effect of amaranth grain flour on the quality of bread. Int. J. Food Prop. 2001, 4, 341-351. [CrossRef]

42. Sanz-Penella, J.M.; Wronkowska, M.; Soral-Smietana, M.; Haros, M. Effect of whole amaranth flour on bread properties and nutritive value. LWT-Food Sci. Technol. 2013, 50, 679-685. [CrossRef]

43. Sindhuja, A.; Sudha, M.L.; Rahim, A. Effect of incorporation of amaranth flour on the quality of cookies. Eur. Food Res. Technol. 2005, 221, 597. [CrossRef]

44. Minervini, F.; Lattanzi, A.; De Angelis, M.; Di Cagno, R.; Gobbetti, M. Influence of artisan bakery-or laboratory-propagated sourdoughs on the diversity of lactic acid bacterium and yeast microbiotas. Appl. Environ. Microbiol. 2012, 78, 5328-5340. [CrossRef] [PubMed] 
45. Ventimiglia, G.; Alfonzo, A.; Galluzzo, P.; Corona, O.; Francesca, N.; Caracappa, S.; Moschetti, G.; Settanni, L. Codominance of Lactobacillus plantarum and obligate heterofermentative lactic acid bacteria during sourdough fermentation. Food Microbiol. 2015, 51, 57-68. [CrossRef] [PubMed]

46. Lattanzi, A.; Minervini, F.; Di Cagno, R.; Diviccaro, A.; Antonielli, L.; Cardinali, G.; Cappelle, S.; De Angelis, M.; Gobbetti, M. The lactic acid bacteria and yeast microbiota of eighteen sourdoughs used for the manufacture of traditional Italian sweet leavened baked goods. Int. J. Food Microbiol. 2013, 163, 71-79. [CrossRef] [PubMed]

47. Vollmannova, A.; Margitanova, E.; Tóth, T.; Timoracka, M.; Urminska, D.; Bojňanská, T.; Čičová, I. Cultivar influence on total polyphenol and rutin contents and total antioxidant capacity in buckwheat, amaranth, and quinoa seeds. Czech J. Food Sci. 2013, 31, 589-595. [CrossRef]

48. Liukkonen, K.H.; Katina, K.; Wilhelmsson, A.; Myllymaki, O.; Lampi, A.M.; Kariluoto, S.; Piironen, V.; Heinonen, S.M.; Nurmi, T.; Adlercreutz, H.; et al. Process-induced changes on bioactive compounds in whole grain rye. Proc. Nutr. Soc. 2003, 62, 117-122. [CrossRef] [PubMed]

49. Poutanen, K.; Flander, L.; Katina, K. Sourdough and cereal fermentation in a nutritional perspective. Food Microbiol. 2009, 26, 693-699. [CrossRef]

50. Park, K.B.; Oh, S.H. Production of yogurt with enhanced levels of gamma-aminobutyric acid and valuable nutrients using lactic acid bacteria and germinated soybean extract. Bioresour. Technol. 2007, 98, 1675-1679. [CrossRef]

51. Kim, J.Y.; Lee, M.Y.; Ji, G.E.; Lee, Y.S.; Hwang, K.T. Production of $\gamma$-aminobutyric acid in black raspberry juice during fermentation by Lactobacillus brevis GABA100. Int. J. Food Microbiol. 2009, 130, 12-16. [CrossRef]

52. Thwe, S.M.; Kobayashi, T.; Luan, T.; Shirai, T.; Onodera, M.; Hamada-Sato, N.; Imada, C. Isolation, characterization, and utilization of $\gamma$-aminobutyric acid (GABA)-producing lactic acid bacteria from Myanmar fishery products fermented with boiled rice. Fish. Sci. 2011, 77, 279-288. [CrossRef]

(C) 2019 by the authors. Licensee MDPI, Basel, Switzerland. This article is an open access article distributed under the terms and conditions of the Creative Commons Attribution (CC BY) license (http://creativecommons.org/licenses/by/4.0/). 